Psychology. Journal of the Higher School of Economics.

2019. Vol. 16. N 1. P. 164-180. DOI: 10.17323/1813-8918-2019-1-164-180

\title{
CONTROLLED DISCOVERY: THE EXECUTIVE FUNCTIONS IN INSIGHT PROBLEM SOLVING
}

\author{
A.D. SAVINOVA ${ }^{\mathrm{a}}$, S.YU. KOROVKIN ${ }^{\mathrm{a}}$
}

${ }^{a}$ Yaroslavl Demidov State University, 9 Matrosova Lane, Yaroslavl, 150057, Russian Federation

\begin{abstract}
Executive functions could play an important role in insight problem solving, however their character, content, and pattern of dynamics may significantly differ from the role of executive functions in non-insight problems. We employed a dual-task paradigm with probe-tasks to track the dynamics of executive functions load in working memory. Two experiments in which we investigated the dynamics of executive functions load in insight and non-insight problems with simultaneous implementation of the Eriksen flanker test are described. Differences in the dynamics of various executive functions in insight problem solving were not revealed. But we found that the dynamics of reaction time in the probe-tasks differs between insight and non-insight problem solving. The results reveal that insight problem solving demands less executive resources, but the executive functions load is significantly greater than the baseline. Also we found that various phases of insight problems require different amount of executive resources. The non-insight problems featured a significant executive functions load after the phase of reading the problem. In insight problem solving we observed an improvement of probe-tasks performance after the phase of reading the problem in the middle of the problem solving process. We speculate that this result reveals an impasse phase that is related to an executive functions load decrease. Surprisingly, we observed a significant increase in the executive functions activity immediately prior to the awareness of a solution. It might be due to controlled solution processing after noticing new elements of a problem that lead to the final solution.
\end{abstract}

Keywords: insight, problem solving, executive functions, conflict detection.

\section{Introduction}

Enough controversies have accumulated in the field of insight research regarding the question: are there any specific insight processes for creative problem solving (Ohlsson, 2011; Weisberg, 2015)? On the one hand, some data indicates that insight problems are simply a variety of intellectual problems and therefore they do not require any special processes (Kaplan \& Simon, 1990). On the other hand,

This work was supported by the Ministry of Education and Science of the Russian Federation under Grant 25.5666.2017/8.9; and the Russian Foundation for Basic Research under Grant 18-013-01056. 
some data indicates the necessity for special mechanisms for insight problem solving (Öllinger, Jones, Faber, \& Knoblich, 2012).

Duncker (1945) suggested that problem conditions in insight problem solving do not allow us to find the correct answer, because there is a contradiction (conflict) between requirements (goal) and the conditions of a problem. The aim of a solver is to determine and resolve this contradiction. The resolution of various conflicts presupposes the special processes of conflict detection. The current data of brain correlates of creativity and insight indirectly indicates the importance of conflict detection functions in insight problem solving. A number of studies on brain activity in creative problem solving point to a significant activity in the anterior cingulate cortex (ACC) in insight and artistic creation, but not in creativity (Dietrich, Kanso, 2010). The work of ACC accompanies the discovery of unexpected failures, and perhaps provides conflict monitoring and the detection of contradictions (Botvinick, Nystrom, Fissell, Carter, \& Cohen, 1999).

The work of ACC is a part of the executive functions. The conflict detection executive function involved in contradiction resolution within a problem could be a part of insight problem solving. Therefore the executive functions could be important in insight, but conflicting results were obtained in research of the role of executive functions in insight problem solving. Numerous attempts to explain insight problem solving from the problem space theory viewpoint aimed at explaining insight through step-by-step algorithms and control (Kaplan \& Simon, 1990; MacGregor, Ormerod, \& Chronicle, 2001) with the work of the prefrontal cortex. At the same time, as shown in several studies (Jarosz, Colflesh, \& Wiley, 2012; Reverberi, Toraldo, D'Agostini, \& Skrap, 2005), prefrontal cortex disruption results in in the improved creative problem solving. At first sight, it is possible to detect a significant contradiction between the statements: "the executive functions (working memory) play an important role in insight problem solving" versus "the executive functions (working memory) do not play an important role in insight problem solving" (Chein \& Weisberg, 2014; Lavric, Forstmeier, \& Rippon, 2000). This discrepancy could be resolved if we accept that working memory involves various independent executive functions. In that case, if one function (such as updating or control), is broken, busy or locked, the other function (for example, conflict detection), may be operated independently.

We propose that different executive functions could play different roles during the process of problem solving. Each executive function performs its role in a problem depending on the pliability of the problem material. The role may include not only constant activity, but local activities in some episodes of solving. The local activities of executive functions could play an important role in problem solving, but at the same time they may hardly be measured by methods that summarize the activity of the entire process in the problem. Hypothetically, cognitive control provides understanding of problem requirements during the initial stages while conflict detection is a crucial component of impasse overcoming. Thus, we need a method that tracks the dynamics of executive functions during different stages of problem solving to understand the insight processes. 


\section{Method}

The executive functions of working memory in problem solving are studied with traditional methods, using a result-oriented approach. The traditional approach suggests the influence (or relation) of an executive function on the efficiency of problem solving. Using data from neural activity studies and a working memory distraction method allowed us to draw conclusions about the role of some functions in general. We introduce an indirect method of the assessment of executive functions dynamics in working memory via a probe-task. We use the probetask based on Kahneman's (1973) resource model and his experimental technique.

According to the resource model, the cognitive resource is allocated to execute different tasks. If tasks are performed simultaneously, the resource is allocated according to the subjective importance (the effectiveness of one task depends on another task: if the primary task requires more resources for its implementation, this amount will be taken from the secondary, or additional, task. In this case, the effectiveness of the additional task will degrade or the additional task may be canceled).

Our method is based on the competition between different tasks for the general cognitive resource in working memory. We used a probe-task to track and reveal changes in working memory. The probe-task is an implementation of the additional task throughout the primary task (in our case the primary task is problem solving). The dynamics of resource demands in the primary problem may be seen via the reaction time dynamics of the probe-task. If the reaction time in dual task trials is greater than in single task trials, then the primary task requires more resources.

\section{Experiment 1}

This experiment was aimed at selecting a relevant probe-task to insight solution. Various probe-tasks are related to different functions, and they could detect various patterns of dynamics in insight problem solving.

The main purpose of this study was to test the hypothesis that the insight solution has specific patterns of executive functions load that rely on the conflict detection. This general hypothesis can be specified in three partial hypotheses: 1 . The dynamics of executive functions load are different in insight and non-insight problems. 2. There is a specific pattern in the dynamics of executive functions load in insight problems, i.e. there is the significant dynamic of the reaction time in probetasks in insight problems. 3. Conflict detection is a specific mechanism of the executive functions in the insight solution. The third hypothesis can be verified if two conditions are met: 3.1. There is an influence of conflict probe-tasks on the dynamics of the reaction time in insight problems; 3.2. There is a significant increase in the reaction time in conflict tasks in the middle stages of the insight solution.

To test these hypotheses, we employed the $2 \times 2 \times 10$ factorial within-subject design. The first factor was primary a problem-type with two levels: insight and non-insight. The second factor was a probe-task with two levels: conflict and non-conflict. The 
stage acted as a grouping variable with ten levels (stages). The only dependent variable is a reaction time in the probe-task.

\section{Method}

\section{Participants}

Participants were 32 (23 women) people, aged 20 to $27(\mathrm{M}=21.78$; $\mathrm{SD}=1.41)$. The majority of the sample consisted of undergraduate and graduate students of Yaroslavl State University. All participants were tested individually, took part voluntarily, and were not paid for their participation.

\section{Stimuli}

We employed the dual task paradigm that included insight and non-insight problems as the primary task, and the probe-task as the additional task. A modified Eriksen flanker test was employed as the probe-task. The flanker test as well as the Stroop test is a well-established correlate of the ACC activity (Botvinick et al., 1999). This probe-task is simple and it may be performed simultaneously with the primary problem.

The two following types of probe-tasks were employed in Experiment 1.

(a) The non-conflict task.

Participants were shown the pictures of two alternatives: a row of five arrows directed to the left and a row of five arrows directed to the right. Participants were instructed to respond by pressing the left key if they saw the row of arrows directed to the left and the right key button if they saw the row of arrows directed to the right. The participants' goal was to perform the task as quickly and accurately as possible.

(b) The conflict task.

Participants performed the same task, except that the central arrow had an opposite direction: if the flanker arrows were directed to the left, the central arrow was directed to the right, and vice versa (Fig. 1). Participants were instructed to respond by pressing the left key if they saw the central arrow directed to the left and the right key if they saw the central arrow directed to the right ignoring the flanker arrows.

All probe-tasks were presented in the center of a screen. The row of arrows included five black arrows on a white background. A mask consisting of black crosses on a white background was presented between stimuli.

We used two types of problems as primary tasks:

\section{An Example of Stimuli Used in Experiment 1}

Figure 1

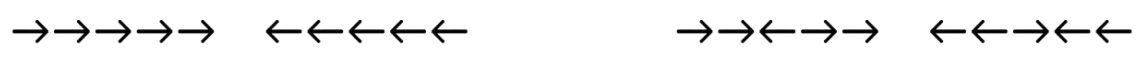


(a) Non-insight problems.

These problems have clear conditions, the algorithm of solution, and the answer logic. Participants know all important operators to find a correct solution. The example of a non-insight problem: "How can you divide 9 apples into equal parts if we have 12 children and we cannot cut an apple into more than 4 parts?" (Answer: Every child will receive 3 parts of an apple).

(b) Insight problems.

These problems require a change of operators or a system wherein the participant does not know a new system of operators. Answers are found suddenly and the process is often associated with an emotional response. The example of an insight problem: "How can you take one from 29 and get 30?" (Answer: XXIX -> XXX).

The problems used in the experiment were balanced in average solution time. The average solution time was ranked by the time needed for problem solving in a single task.

The experiment was performed with PsychoPy2 scripts version 1.81 .02 (Peirce, 2008) on the Asus X550V computer with a 15.6" screen.

\section{Procedure}

All participants exercised in practice trials (single probe-tasks without problem solving) before the experimental trials. The practice trials included a single performance of each type of the probe-tasks. In this experiment we employed three types of practice trials: (a) a simple choice between two alternatives (red or green squares were presented to a participant; if the participant saw a red square, they should press the right arrow on the keyboard, if they saw a green square - the left arrow); (b) the non-conflict condition; (c) the conflict condition. The simple choice task with colored squares was employed only in the practice trials. Instructions were presented to participants in-between the probe-tasks.

When the participants had performed the practice trials, they proceeded to the experimental trials. Each participant attempted to solve 16 problems ( 8 insight problems and 8 non-insight problems) with various probe-tasks (the conflict and non-conflict conditions). The problems were presented on the top of a screen. All problems and probe-tasks were presented in random order. The participants solved the problems and at the same time they performed the probe-tasks, which lasted throughout the problem solving session. The probe-task trials repeated indefinitely for as long as it took to finish the primary problem. The participants solved the problems verbally. If the participants could not suggest a hypothetical solution after more than two minutes, the experimenter gave them a verbal hint. After the solution of the problem, the participants had a break (no more than one minute) and then proceeded to the next problem.

To control the influence of verbalization on the increase in the reaction time in the last stages we analyzed the data of insight problems performance from the beginning of the problem until the moment when the participants expressed an emotional reaction (found a solution principle) prior to the verbalization of the correct answer. The experimenter registered markers of the insight whenever they 
occurred. Data record for insight problems stopped after a participant's emotional reaction or a solution principle were found. Data record for the non-insight problems stopped after the correct answer was reported.

A participant's reaction time was recorded in milliseconds and used to assess the dynamics of the cognitive processes. We assume that a greater reaction time in the probe-task indicates that lesser cognitive resources were allocated to the probetask due to greater cognitive resource demands of primary problem solving. Thus, the reaction times in the probe-tasks are indicative of the executive functions load dynamics.

\section{Data analysis}

Each of 32 participants solved 16 problems (512 problems in total), but some problem solving trials were excluded: we excluded unsolved problems; trials that had the reaction times more 20 seconds (in this case we assumed that participants did not cope with the simultaneous implementation of two tasks); problems that were solved in less than 50 seconds (due to the possibility that participants already knew the answer). Remaining 317 experimental situations (173 insight trials and 144 non-insight trials) were averaged for each participant.

After collecting the data and excluding some trials we divided each problem in 10 stages that were equal in time. We adhered to the requirement of maximum divisibility and suggested that 10 stages are optimal for our goals, but the number of stages is contingent. We consider each stage as an equal time interval that is not definitely related to certain problem solving phases. The division into 10 stages is useful to track the dynamics and overlap patterns of resources allocation during various problems. The phases with various cognitive processes (comprehension, representational change, impasse, etc.) could be established through the analysis of quantitative data obtained within these stages.

We found the average reaction time in the probe-tasks in each of 10 stages. The next step of our data analysis was to collect all the average reaction times in each stage of the solution from each participant. The value of each stage of the solution represents the average reaction time of each participant in this stage of the problem solving. Thus, we are able to combine each participant's solution times into a single data structure. We have found the average reaction time of the probe-task during various stages of solving insight and non-insight problems separately. Besides, we have obtained the data on the average reaction time during various stages in conflict and non-conflict conditions.

Extreme values of reaction times above 3 IQR in every stage were identified as outliers. Trials with the outliers as the stage values were excluded from further analysis. Then we averaged different trials in every condition for every participant. Finally we analyzed 58 averaged trials in the conflict condition (32 insight and 26 non-insight problems) and 58 trials in the non-conflict condition (30 insight and 28 non-insight problems). 


\section{Results}

A three-way repeated measures ANOVA was conducted to test for the main effects and interaction between the problem factor (insight vs. non-insight), the probe-task factor (conflict vs. non-conflict), and the stage factor (stages 1 to 10) on the reaction times. Mauchly's test of sphericity indicated that the assumption of sphericity was violated, therefore a Greenhouse-Geisser correction was used. The results revealed the main effect of problem types $\left(\mathrm{F}(1,24)=36.95, p<.001, \eta_{\mathrm{p}}{ }^{2}=.61\right)$ on the reaction time. The values of the reaction time during non-insight problems were greater $(\mathrm{M}=1.35, \mathrm{SD}=0.64)$ than those in insight problems $(\mathrm{M}=1.07$, $\mathrm{SD}=0.48)$. The results also revealed the main effect of the stage factor $(\mathrm{F}(5.14$, $\left.123.41)=9.74, p<.001, \eta_{\mathrm{p}}^{2}=.29\right)$, and a significant interaction between the problem and stage factors $\left(\mathrm{F}(4.57,109.57)=4.46, p=.001, \eta_{\mathrm{p}}^{2}=.16\right)$. This means that we found different patterns of the probe-tasks dynamics during insight and noninsight problems (Figure 2).

A one-way repeated measures ANOVA with a Greenhouse-Geisser correction revealed the main effect of the stage factor among non-insight problems $(\mathrm{F}(5.65$, $\left.135.57)=8.1, p<.001, \eta_{\mathrm{p}}{ }^{2}=.252\right)$ as well as among insight problems $(\mathrm{F}(3.76$, $\left.109.05)=4.46, p=.004, \eta_{\mathrm{p}}{ }^{2}=.125\right)$. Executive functions load significantly vary from stage to stage in insight and non-insight problems differently.

We can see an increase in the reaction time of the probe-tasks in non-insight problems from the fourth stage and onwards until the last stage. The same described pattern of the dynamics of executive functions load was observed in both the conflict and non-conflict probe-task conditions. The results of a two-way repeated measures ANOVA with a Greenhouse-Geisser correction did not reveal

Figure 2

The Executive Functions Load Dynamics in Insight and Non-Insight Problem Solving in All Conditions. Vertical bars denote .95 confidence intervals.

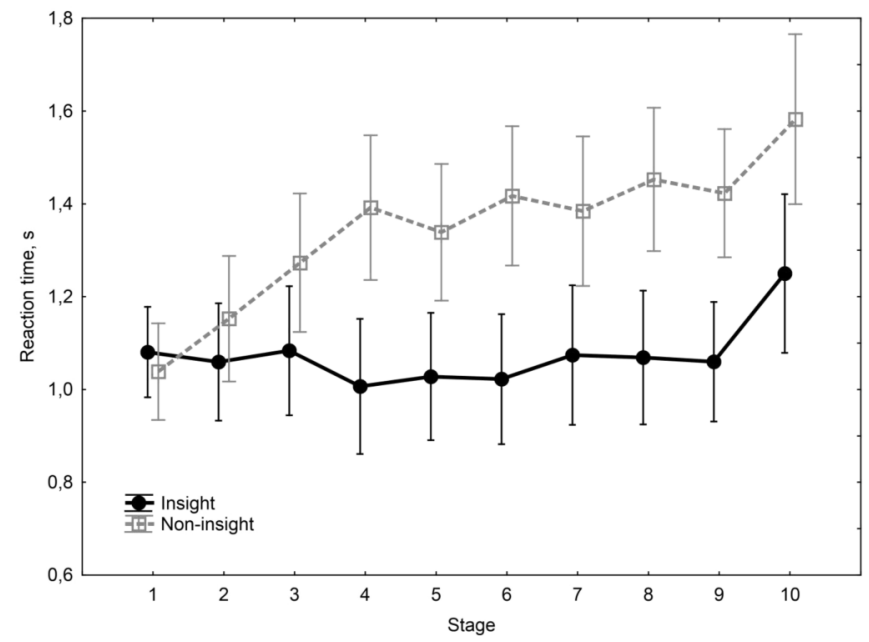


any interaction between the probe-task and the stage factors in non-insight problem solving $\left(\mathrm{F}(4.16,88.8)=0.81, p=.527, \eta_{\mathrm{p}}^{2}=.033\right)$. Thus, the increase of reaction time in the non-insight problems is resistant to various probe-task conditions. The dynamics of executive functions load in non-insight problems reveals a gradual increase of the reaction time. We speculate that this increase is associated with working memory load: one needs to keep the problem in mind, store intermediate solutions, predict next steps, etc. Non-insight problem solving generally competes with the probe-tasks more than the insight problems. We argue that the results show that non-insight problems require more cognitive resource and they are related to the activity of the central executive of working memory. The revealed pattern of dynamics does not provide a detailed picture but it shows only the overall effect of the executive functions. Thereunder, we can conclude that Hypothesis 1 was confirmed. The dynamics of the executive functions load is different in insight and non-insight problems.

To test the other hypotheses we analyzed the data on insight problem solving. A two-way repeated measures ANOVA with a Greenhouse-Geisser correction within insight problems revealed the main effect of the stage factor $(\mathrm{F}(3.76$, $\left.109.05)=4.15, p=.004, \eta_{\mathrm{p}}^{2}=.125\right)$. We found an increase in the reaction time in the final stages of insight problem solving, especially during the tenth stage. There was a significant dynamics of the reaction time in the probe-task in insight problems (Figure 3). This means that we confirmed Hypothesis 2.

Nevertheless, we did not found a significant interaction between the probe-task factor and the stage factor $\left(\mathrm{F}(5.36,155.52)=2.15, p=.058, \eta_{\mathrm{p}}^{2}=.069\right)$ in insight problem solving. The results of a three-way repeated measures ANOVA with a Greenhouse-Geisser correction did not reveal interaction between the probe-task,

Figure 3

The Dynamics of Insight Problem Solving in the Conflict and Non-Conflict Conditions. Vertical bars denote .95 confidence intervals

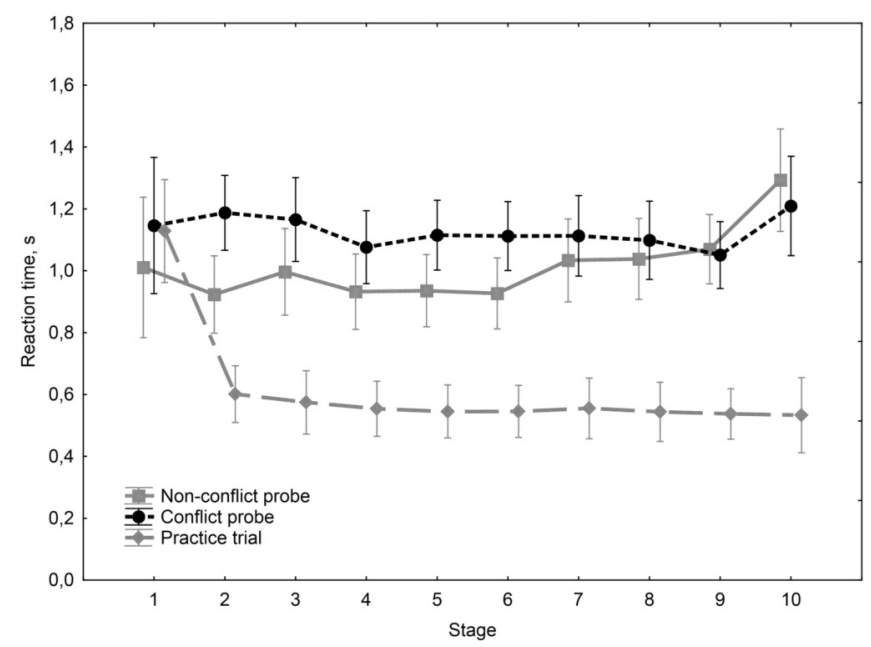


problem and stage factors as well $\left(\mathrm{F}(4.88,117.07)=1.14, p=.341, \eta_{\mathrm{p}}{ }^{2}=.045\right)$. This data does not support Hypotheses 3.1 and 3.2. We found similar patterns of the dynamics in the executive functions load using various probe-tasks. Moreover, we did not find any increase in the reaction time in the middle of problem solving related to conflict detection. At the same time, we observed an unexpected increase in the reaction time in Stage 10.

\section{Discussion}

In Experiment 1 we obtained data that supports the specificity of insight solution, because the results revealed that non-insight problems required a greater involvement of the executive functions than insight problems. Moreover, we observe the same patterns of non-insight problems dynamics in various conditions. This pattern of dynamics was found in previous studies (Korovkin, Vladimirov, \& Savinova, 2014). This tells us that this pattern of the executive functions work is persistent. Although we excluded the period between first markers of an aha-reaction and verbalization of correct answers from the analysis, we observed an increase in the reaction time during the last stages of insight problems. Probably the slowdown of probe-tasks performance during the last stages indicates that the executive functions activity is related to the production of an answer, but not to its verbalization. Thus, we have confirmed Hypothesis 1.

We observed a significant dynamics of executive functions load in insight problem solving that differs from the dynamics in non-insight problems. We argue that various phases of insight problems require different amounts of the executive resources. The results reveal that insight problem solving demands less executive resources, but the executive functions load is significantly greater than in the practice trials. The executive functions load is observed throughout the solution, but there is an increase in the last stage prior to the answer. The specific pattern of executive functions load dynamics in insight problems supports Hypothesis 2.

At the same time we did not find any influence of the probe-task factor on the reaction time in insight problems (Hypothesis 3.1). The differences between the dynamics of the probe-tasks in insight problems are just above .05 p-level. The tests did not reject the null hypothesis that the dynamics in the conflict and non-conflict probe-tasks is similar. In any case, the observed dynamics in both the conflict and non-conflict conditions differs from what we expected to find. Moreover, it is impossible to make clear conclusions about specific peaks of the reaction time increase or decrease in the middle of insight problems (Hypothesis 3.2). Surprisingly we found an increase in the executive functions load prior to the solution discovery.

There are some limitations in this experiment. One would assume that probetasks would benefit from the defocusing of attention. Using the peripheral arrows as a source of information was not controlled in this experiment. Defocusing could shift the attention focus to the periphery and greatly simplify the task. To control for this possibility, we have to use bidirectional peripheral arrows in the probetasks. Therefore, we designed and conducted Experiment 2 to test the pattern of the dynamics observed in Experiment 1. 


\section{Experiment 2}

Experiment 2 was conducted to rectify the shortcomings of the previous study. We modified the probe-tasks by adding bidirectional peripheral arrows to focus participants' attention on the central arrows.

We employed the $4 \times 10$ factorial within-subject design. The first factor was a probe-task with four levels: non-conflict, perceptual conflict, motor conflict, and complex conflict. The stage acted as a grouping variable with ten levels (stages). The only dependent variable is the reaction time in a probe-task.

\section{Method}

\section{Participants}

Participants were 32 (23 women) people, age 13 to $39(\mathrm{M}=20.85$; $\mathrm{SD}=3.99)$. The majority of the sample consisted of undergraduate and graduate students of Yaroslavl State University. All participants were tested individually, took part voluntarily, and were not paid for their participation.

\section{Stimuli}

In this experiment we modified stimuli of the probe-tasks. We added a neutral arrangement of the bidirected arrows row. The addition was necessary to exclude a speculation that Experiment 1 effects may be due to the confounding variable, for example, various conditions for attention switching in conflict and non-conflict tasks. We included new probe-tasks to verify that the strengthening of a conflict leads to more vivid effects in the problem solving dynamics. We employed two types of conflicts: a representational (or perceptual) conflict and a motor conflict. The representational conflict is a conflict between perceived information from the periphery and the motor response. The motor conflict is a conflict between the automatic response and the instruction.

Totally we employed four probe-tasks in Experiment 2:

a) The non-conflict task.

Participants were shown two alternatives: the central arrow was directed either to the left or to the right (Figure 4). Contrary to Experiment 1, this task had a central arrow that was surrounded by congruent or neutral flanker arrows. Participants were instructed to respond by pressing the left key if they saw the central arrow directed to the left and the right key button if they saw the central arrow directed to the right. The participants' goal was to perform the task as quickly and accurately as possible.

b) The perceptual conflict task.

Participants performed the same task, except that the central and flanker arrows pointed in contrary directions. For correct response it was necessary to spot 
Figure 4

An Example of Stimuli Used in Experiment 2

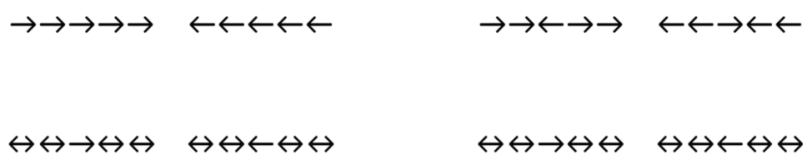

the central arrow direction and to press the appropriate key (for example, left arrow - press "left") ignoring the noncongruent flanker arrows.

c) The motor conflict task.

A row of arrows was presented to participants as in a non-conflict task but instruction demands to conversely respond to the central arrows direction. If the central arrow was directed to the right, the participant had to press the left key and vice versa.

d) The complex conflict task.

This task is similar to the perceptual conflict task but with an inverse instruction as in the motor conflict task. We expected that this task was the most difficult due to both the perceptual and motor conflicts.

All probe-tasks were presented in the center of a screen. The rows of arrows included five black arrows on a white background. A mask consisting of black crosses on a white background was presented between stimuli.

In Experiment 2 we used only 8 insight problems. Problems were presented on the top of a screen. All problems were controlled for difficulty levels.

\section{Procedure}

Participants solved problems and at the same time performed the probe-tasks. The experiment was designed similarly to Experiment 1 (it also included practice trials with each probe-task in the single task condition before the experiment).

\section{Data analysis}

Each participant solved 8 insight problems (256 in total). But we excluded unsolved problems; trials with the reaction time values of more than 20 seconds and trials with more than $50 \%$ of errors in the probe-task (in these cases we assumed that participants did not cope with the simultaneous implementation of two tasks); problems that have been solved in under 50 seconds (due to the possibility that participants already knew the answer). Thus, we obtained 161 data points for statistical analysis. The next steps of the data analysis were the same as in Experiment 1. We excluded the cases with outliers of the reaction time above 3 IQR in every stage. Finally we analyzed 23 averaged trials in the non-conflict condition, 20 averaged trials in the perceptual conflict condition, 21 averaged trials 
in the motor conflict condition, and 26 averaged trials in the complex conflict condition divided into 10 stages.

\section{Results}

A two-way repeated measures ANOVA with a Greenhouse-Geisser correction revealed the main effect of the stage factor on the reaction time values $(\mathrm{F}(3.9$, $\left.46.85)=4.01, p=.007, \eta_{\mathrm{p}}^{2}=.25\right)$. The analysis did not reveal the main effect of the probe-task factor on the reaction time $\left(\mathrm{F}(3,36)=0.1, p=.959, \eta_{\mathrm{p}}^{2}=.008\right)$ as well as interaction between the stage and probe-task factors $(\mathrm{F}(6.29,75.48)=0.47, p=.834$, $\left.\eta_{\mathrm{p}}^{2}=.038\right)$. These results indicate that there is no significant differences in patterns of the executive functions load in various probe-tasks (Figure 5).

A one-way repeated measures ANOVA with a Greenhouse-Geisser correction demonstrated that there are significant changes in the executive functions load dynamics in the non-conflict $\left(\mathrm{F}(5.25,115.6)=2.32, p=.045, \eta_{\mathrm{p}}^{2}=.095\right)$, perceptual conflict $\left(\mathrm{F}(3.9,74.03)=5.36, p=.001, \eta_{\mathrm{p}}^{2}=.22\right)$, motor conflict $(\mathrm{F}(3.67,73.43)$ $\left.=2.59, p=.048, \eta_{\mathrm{p}}^{2}=.115\right)$, and complex conflict $(\mathrm{F}(3.99,99.79)=4.81, p=.001$, $\left.\eta_{\mathrm{p}}^{2}=.161\right)$ conditions.

Generally the dynamics of executive functions load in insight problems was significant and had the same pattern as in Experiment 1 (Figure 6). We may see the

Figure 5

The Dynamics of Insight Problems Solving in the Probe-Task Conditions.

Vertical bars denote .95 confidence intervals
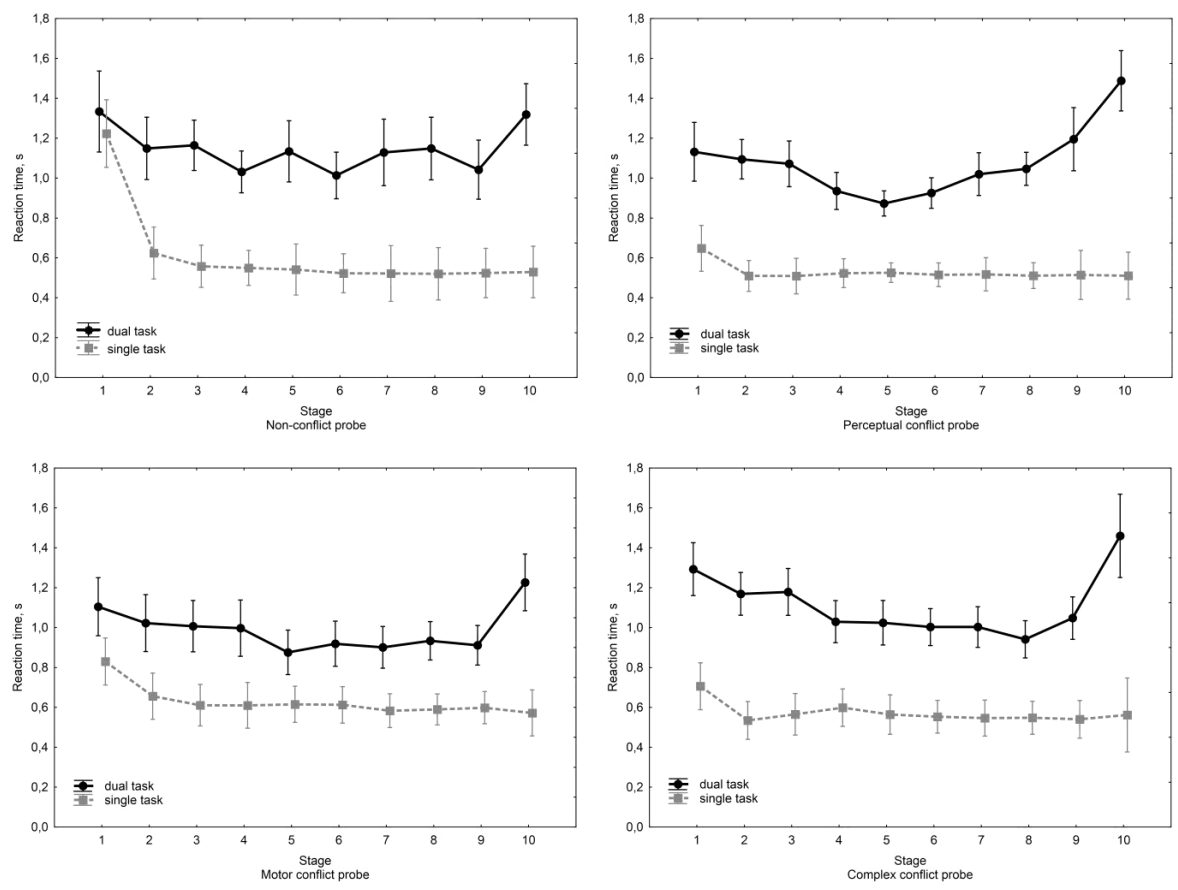
Figure 6

The Average Dynamics of the Executive Functions Load in Insight Problem Solving. Vertical bars denote .95 confidence intervals

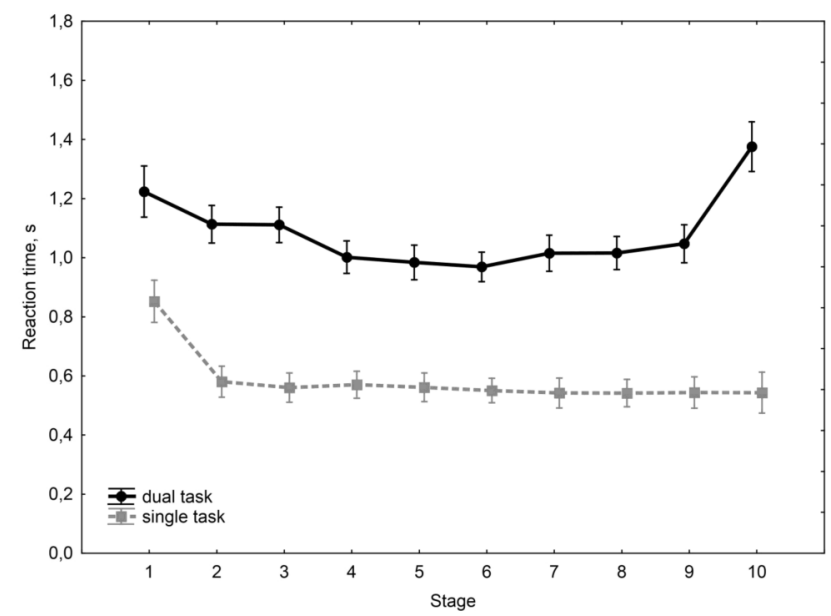

similar dynamics in every probe-task with local declines in the middle of the solution and an abrupt increase in the executive functions load in the last stage of the solution. Thus, we may conclude that hypothesis 2 was confirmed. There is a specific pattern of the dynamics of executive functions load in insight problems.

Unexpectedly, the probe-task factor in Experiment 2 did not indicate a significant effect on the dynamics of the reaction time. Despite the fact that the complex conflict condition includes very conflicting processes we did not reveal any significant differences from the other probe-tasks. Similarly, there is no pronounced increase of the reaction time in the conflict tasks in the middle stages. Therefore there is no evidence to confirm Hypotheses 3.1 and 3.2.

\section{Discussion}

The results of Experiment 2 support the findings of Experiment 1. We found a robust pattern of the executive functions load during insight problem solving. As well as in the results in the previous experiment, Experiment 2 revealed a decrease in the reaction time in the middle stages in insight problem solving. We argue that the first part of insight problem solving involves an average level of the executive functions activity, the middle part of problem solving has a decrease in the executive functions activity, and the last part of problem solving features an abrupt reaction time increase immediately prior to the correct answer finding.

These results are the opposite to what we initially expected. Nevertheless, we found other remarkable features of the reaction time dynamics in insight problem solving. The revealed increase in the reaction time in Stage 10 in all conditions indicates the executive functions activity prior to solution finding. We suggest that insight processes such as representational change could occur during this period. 
Apparently, the final period of a solution is extremely demanding in terms of cognitive resource.

Similarly, we think that a decline of the reaction time in the middle of solution indicates that an impasse occuring in this phase demands less cognitive control. Since the cognitive resource was no longer needed for problem solving, as the impasse phase is far less cognitive demanding, it was relocated elsewhere - to the probe-task, resulting in the temporary reaction time acceleration. If participants rejected problem solving after the middle of the solution and did not perform any information processing regarding the solution, the reaction time must have been the same in the experiment and practice trials (dual task vs. single task performance). The proof of information processing during the impasse rather than a rejection of the solution is that reaction time in insight problem solving was significantly greater than in the single task even during the sixth stage $(t(31)=6.92$, $p<.001, r=.649$ ) on average for all tasks.

\section{General Discussion}

The results of the experiments revealed differences of the levels and dynamics of the executive functions load between insight and non-insight problems. This data shows that insight problems have the other content of ongoing processes in working memory. The first half of the solution of both problem types equally involves the executive functions that appear to be related to problem comprehension. The resources can be allocated to reading a problem, identifying essential conditions and building a representation based on these conditions. But then patterns of the executive functions become very different. There is a significant increase in the reaction time in non-insight problems in any probe-tasks, which is associated with a crucial involvement of the executive functions in non-insight problem solving process. Meanwhile, it appears that nothing like this happens to the probe-task reaction time in terms of the executive functions in insight problem solving. Moreover, a significant decline of the reaction time occurs in all probe-tasks. However, it does not mean that a solver quits problem solving. A part of the resource continues to be distributed to the problem. Immediately prior to behavioral manifestations of finding a solution (Stage 10), a rise of the reaction time in the probe-tasks during insight problem solving is observed. This indicates a significant resource allocation to insight problem solving even before a solution is found. As shown, the work of the executive functions is not associated with a simple verbalization of the answer, and apparently is aimed at the production of a solution even prior to the awareness of the right answer. Here we need to point out that both automatic (unconscious) and voluntary (conscious) executive functions should be considered. This fact is yet another argument in support of the idea of the existence of unconscious mechanisms of solution preparation prior to insight (Ellis, Glaholt, \& Reingold, 2011; Thomas \& Lleras, 2009).

Apparently the goal of this study - to find a relevant probe-task to insight problems - was achieved. The Eriksen flanker test as a probe-task can be used to reveal the dynamics of the executive functions load in insight problem solving. 
Nevertheless, the modifications of the probe-task did not reveal any significant differences in the dynamics. This means that we cannot come to a conclusion about various executive functions during different stages. Thus the main hypothesis of this study that an increase in the reaction time in the probe-task related to activating the conflict detection could be revealed before finding the solution of insight problem was not confirmed.

On the contrary, we observe an opposite picture with a slight acceleration of the reaction time in all probe-task regardless of the conflict features. It could be assumed that the decrease in response time is due to the fact that the primary problem just fades into the background and attention focuses on the probe-task, which ceases to be secondary. An insight problem becomes secondary and continues to be processed. Also we observe a steady rise of the executive functions load during the final stages just prior to the detection of the correct solution. This pattern is typical for dynamics of all kinds of probe-tasks. This allows us to speak about the modulation of general executive functions activity before finding the correct solution. The fact that the executive functions load steadily increases before an aha-moment suggests that insight is associated with the implementation of latent automatic executive functions in problem solving.

Thus, we can conclude that the executive functions play an important role in insight problem solving. At the beginning of problem solving it is necessary to comprehend a problem and to develop solutions in the end. In the middle of problem solving there is a significant decrease in the reaction time related, in our opinion, to the inhibition of the executive functions. At the same time, we have no direct evidence of the conflict detection and monitoring function activity in insight problem solving. This is due possibly to the short duration (instantaneity) of this process.

\section{References}

Botvinick, M. M., Nystrom, L. E., Fissell, K., Carter, C. S., \& Cohen, J. D. (1999). Conflict monitoring versus selection-for-action in anterior cingulate cortex. Nature, 402, 179-181. http://doi.org/10.1038/46035

Chein, J. M., \& Weisberg, R. W. (2014). Working memory and insight in verbal problems: analysis of compound remote associates. Memory and Cognition, 42(1), 67-83. http://doi.org/10.3758/ s13421-013-0343-4

Dietrich, A., \& Kanso, R. (2010). A review of EEG, ERP, and neuroimaging studies of creativity and insight. Psychological Bulletin, 136(5), 822-848. http://doi.org/10.1037/a0019749

Duncker, K. (1945). On problem-solving. Psychological Monographs, 58(5), i-113. http://doi.org/10.1037/h0093599

Ellis, J. J., Glaholt, M. G., \& Reingold, E. M. (2011). Eye movements reveal solution knowledge prior to insight. Consciousness and Cognition, 20(3), 768-776. http://doi.org/10.1016/j.concog.2010.12.007

Jarosz, A. F., Colflesh, G. J. H., \& Wiley, J. (2012). Uncorking the muse: Alcohol intoxication facilitates creative problem solving. Consciousness and Cognition, 21(1), 487-493. http://doi.org/ 10.1016/j.concog.2012.01.002 
Kahneman, D. (1973). Attention and effort. Englewood Cliffs, NJ: Prentice-Hall, Inc.

Kaplan, C. A., \& Simon, H. A. (1990). In search of insight. Cognitive Psychology, 22(3), 374-419. http://doi.org/10.1016/0010-0285(90)90008-R

Korovkin, S., Vladimirov, I., \& Savinova, A. (2014). The dynamics of working memory load in insight problem solving. The Russian Journal of Cognitive Science, 1(4), 67-81. Retrieved from http://cogjournal.org/1/4/pdf/KorovkinVladimirovSavinovaRJCS2014.pdf

Lavric, A., Forstmeier, S., \& Rippon, G. (2000). Differences in working memory involvement in analytical and creative tasks: an ERP study. Cognitive Neuroscience, 11(8), 1613-1618. http://doi.org/10.1097/00001756-200006050-00004

MacGregor, J. N., Ormerod, T. C., \& Chronicle, E. P. (2001). Information processing and insight: A process model of performance on the nine-dot and related problems. Journal of Experimental Psychology: Learning, Memory and Cognition, 27(1), 176-201. http://doi.org/10.1037//0278-7393.27.1.176

Ohlsson, S. (2011). Deep learning. How the mind overrides experience. Cambridge, UK: Cambridge University Press.

Öllinger, M., Jones, G., Faber, A. H., \& Knoblich, G. (2012). Cognitive mechanisms of insight: The role of heuristics and representational change in solving the eight-coin problem. Journal of Experimental Psychology: Learning, Memory, and Cognition, 39(3), 931-939. http:/doi.org/ $10.1037 / \mathrm{a} 0029194$

Peirce, J. W. (2008). Generating stimuli for neuroscience using PsychoPy. Frontiers in Neuroinformatics, 2. http://doi.org/10.3389/neuro.11.010.2008

Reverberi, C., Toraldo, A., D’Agostini, S., \& Skrap, M. (2005). Better without (lateral) frontal cortex? Insight problems solved by frontal patients. Brain, 128(12), 2882-2890. http://doi.org/10.1093/brain/awh577

Thomas, L. E., \& Lleras, A. (2009). Covert shifts of attention function as an implicit aid to insight. Cognition, 111(2), 168-174. http://doi.org/10.1016/j.cognition.2009.01.005

Weisberg, R. W. (2015). Toward an integrated theory of insight in problem solving. Thinking and Reasoning, 21(1), 5-39. http://doi.org/10.1080/13546783.2014.886625

Wiley, J., \& Jarosz, A. F. (2012). How working memory capacity affects problem solving. In B. H. Ross (Ed.), Psychology of learning and motivation (Vol. 56, pp. 185-227). San Diego, CA: Elsevier Inc. http://doi.org/10.1016/B978-0-12-394393-4.00006-6

Anna D. Savinova - Ph.D. student, Department of Psychology, Yaroslavl Demidov State University.

Research area: cognitive psychology.

E-mail: anuta1334@yandex.ru

Sergei Yu. Korovkin - associate professor, Department of Psychology, Yaroslavl Demidov State University, Ph.D.

Research area: cognitive psychology.

E-mail: korovkin_su@list.ru 


\title{
Контролируемое открытие: управляющие функции в решении инсайтных задач
}

\author{
А.Д. Савинова ${ }^{a}$ С.Ю. Коровкин \\ ${ }^{a}$ ФГБОУ ВО «Ярославский государственный университет им. П.Г. Демидова», 150057, Россия, \\ Ярославль, пр. Матросова, д. 9
}

\section{Резюме}

Управляющие функции могут играть важную роль в решении инсайтных задач, однако их характер, содержание и паттерны динамики могут существенно отличаться от роли управляющих функций в решении неинсайтных задач. Мы использовали парадигму двойной задачи с использованием заданий-зондов для отслеживания динамики загрузки управляющих функций в рабочей памяти. В статье описаны два эксперимента, в которых исследовалась динамика загрузки управляющих функций в процессе решения инсайтных и неинсайтных задач одновременно с выполнением флангового задания Эриксена. Не было выявлено различий в динамике разных типов управляющих функций при решении инсайтных задач. Однако было обнаружено, что динамика времени реакции при выполнении заданий-зондов различается при решении инсайтных и неинсайтных задач. Эти результаты показывают, что инсайтные задачи менее требовательны к ресурсам управляющих функций, хотя загрузка значительно выше фонового уровня. Также выявлено, что на различных этапах решения задачи требуется разное количество ресурсов управляющих функций. Неинсайтные задачи проявляют значимую загрузку управляющих функций после этапа чтения задачи. В инсайтных задачах, напротив, наблюдается улучшение выполнения заданий-зондов после этапа чтения задачи в середине процесса решения задачи. Мы считаем, что этот результат выявляет этап тупика, который связан со снижением загрузки управляющих функций. Неожиданно были получены данные о наличии значимого увеличения активности управляющих функций непосредственно перед осознанием решения. Это может быть связано с необходимостью контролируемого процесса решения после того, как испытуемый замечает новые элементы задачи, ведущие к итоговому решению.

Ключевые слова: инсайт, решение задач, управляющие функции, обнаружение противоречий.

Савинова Анна Джумберовна - аспирант, кафедра общей психологии, факультет психологии, Ярославский государственный университет им. П.Г. Демидова.

Сфера научных интересов: когнитивная психология.

Контакты: anuta1334@yandex.ru

Коровкин Сергей Юрьевич - доцент, кафедра общей психологии, факультет психологии, Ярославский государственный университет им. П.Г. Демидова, кандидат психологических наук.

Сфера научных интересов: когнитивная психология.

Контакты: korovkin_su@list.ru 